\title{
Determining the mental model of experts regarding the factors hindering the development of table tennis in Iran
}

\section{Determinar el modelo mental de los expertos sobre los factores que obstaculizan el desarrollo del tenis de mesa en Irán}

\author{
Maryam Zeinal Famileh \\ $\mathrm{PhD}$ student in Sports Management, Islamic Azad University, Mashhad Branch, Iran \\ Hassan Fahim Devin \\ Assistant Professor, Islamic Azad University, Mashhad Branch, Iran \\ Mohammad Reza Esmaeilzadeh \\ Assistant Professor, Islamic Azad University,Mashhad Branch, Iran \\ Hossin Peymanizad \\ Associate Professor, Islamic Azad University, Mashhad Branch, Iran
}

*Correspondence

Email: HassanFahim@gmail.com
Cite as:

Famileh, M.Z., Fahim Devin, H., Reza Esmaeilzadeh, M., \& Peymanizad, H. (2021). Determining the mental model of experts regarding the factors hindering the development of table tennis in Iran. Propósitos y Representaciones, 9 (SPE1), e834. Doi: http://dx.doi.org/10.20511/pyr2021.v9nSPE1.e834 


\section{Summary}

Determining the mental model of experts regarding the factors hindering the development of table tennis in Iran. The purpose of this study is to determine the mental pattern of experts regarding the barriers to professional table tennis in Iran using Q methodology. The present study is applied in terms of purpose; In terms of exploratory nature; In terms of data collection, descriptive-survey, and due to application, Q methodology is a type of mixed research (quantitative-qualitative). The statistical population was veterans and elites in table tennis in Iran, from which 21 people were selected as participants through a combination of purposeful and unlikely sampling and snowball sampling. Participant sorting data were entered in SPSS software to identify the different mindsets of the participants using Q-factor analysis. Finally, the main deterrents in Iranian professional table tennis were prioritized based on nine mental patterns. These mental patterns were then discussed and interpreted. Finally, coping strategies were proposed.

Keywords: Mental pattern, Q factor analysis, table tennis, inhibitory factors.

\section{Resumen:}

Determinar el modelo mental de los expertos sobre los factores que obstaculizan el desarrollo del tenis de mesa en Irán. El propósito de este estudio es determinar el patrón mental de los expertos con respecto a las barreras al tenis de mesa profesional en Irán utilizando la metodología Q. El presente estudio se aplica en términos de propósito; En términos de naturaleza exploratoria; En términos de recolección de datos, encuesta descriptiva, y por aplicación, la metodología Q es un tipo de investigación mixta (cuantitativa-cualitativa). La población estadística fue de veteranos y élites en el tenis de mesa en Irán, de los cuales 21 personas fueron seleccionadas como participantes mediante una combinación de muestreo intencionado e improbable y muestreo de bola de nieve. Los datos de clasificación de los participantes se ingresaron en el software SPSS para identificar las diferentes mentalidades de los participantes mediante el análisis del factor Q. Por último, los principales elementos de disuasión del tenis de mesa profesional iraní se priorizaron en función de nueve patrones mentales. Estos patrones mentales fueron luego discutidos e interpretados. Finalmente, se propusieron estrategias de afrontamiento.

Palabras clave: patrón mental, análisis del factor Q, tenis de mesa, factores inhibidores.

\section{Introduction}

Today, sport has been accepted by all countries as the most effective social factor to create national pride and increase the health and vitality of society, and the governments of the world try to pay special attention to economic, cultural and political factors. Take advantage of it. Undoubtedly, this will be done in the shadow of strategic planning and drawing visions for many years (Jarvi, 2013). It should be noted that developed countries as well as developing countries each face many problems in their sport. Issues related to culture and media, control through sports, creation of capitalist systems through sports, etc. in developed countries, as well as problems related to sports and educational equipment and facilities, corruption in financial transactions, problems related to education And research in sports, etc. are among the deterrent components in developing countries (Qualter, 2010). On the other hand, the performance of athletes in different sports is associated with different dimensions that can affect the result and the final performance of the athlete. The condition and readiness of the athlete himself, various structural and physical 
factors and various underlying factors will in any way cause differences in the performance of the athlete (Bones et al., 2019). Undoubtedly, the sports field creates an opportunity for feelings and emotions, which may lead to the emergence of stress, aggressive behaviors and marginal issues, and cause the person involved to suffer from negative and malignant psychological pressures, and to analyze strong forces; And ultimately sterilizes activities and efforts (Kang and Bodenhausen, 2015).

Therefore, the sport of table tennis, due to its special charm, is one of the most popular sports communities in the world and has a unique position among other sports, so that it is a pervasive and global phenomenon. It has become and no limit can be set for it. Due to its social, cultural, economic and political dimensions, this field has been completely taken out of the simple game mode (Wang et al., 2019).

Professional table tennis is now one of the most lucrative sports in the world under unprecedented conditions. Professional competitions organized in different leagues of the world are among the complementary economic activities that increase the economic prestige of the countries of the world. Table tennis, as a popular sport in all parts of the world, must be managed in the best possible way to achieve the political, economic, social and cultural goals of nations (Negi, 2013). The growth of table tennis as an industrial phenomenon in the last few decades has been significant in all societies and is one of the most lucrative disciplines in the new century. Launching the Professional Table Tennis League Although in line with the global policies of the Table Tennis Federation in order to commercialize table tennis in member countries, but its development and survival in today's business world requires the provision of tools, equipment, culture, laws and Regulations of their own. Studies conducted around the world indicate that tennis on mSome nations, despite entering the field of professionalism, still have many injuries in their body. Problems related to economic issues, lack of conclusions in national arenas, problems in the field of hardware facilities, neglect of basic table tennis and such issues are among the injuries in the field of table tennis. Table tennis is very different from developing countries in developed countries. Corruption related to financial issues, mismanagement, poor organization of local and club competitions, the existence of cases related to money laundering and collusion in table tennis, the entry of politicians to achieve personal goals, etc., including the problems of table tennis in countries It is considered development (Georg, 2015). For this reason, a more detailed and in-depth examination of the injuries and deterrent components of table tennis in Iran is necessary.

A careful study of the research literature makes it clear that this important issue has not been addressed directly, either internally or externally; Azmandnia (2008) in his research examined the structural and physiological characteristics of elite table tennis players in Iran. Proper training of professional players, paying attention to the physiological criteria of the players, performing standard and purposeful exercises in line with modern training were among the items that Armandnia stated in its research to reduce the gap between Iranian table tennis and advanced table tennis in the world. Was. In this regard, Emadi et al. (2014) compared the effect of modern and traditional educational methods in this sport. Significant differences and correct execution of movements in table tennis in a modern educational method compared to the traditional method are among the main results of this research. Keshtidar et al. (2015) in their research entitled Identifying and Modeling Strategies for the Development of Public Sports among Female Students of Birjand University concluded that the strategies for the development of public sports, respectively, economic, managerial, cultural, infrastructure And facilities are research and educational. Keshtidar et al. (2015) in a study examined and identified the mental 
pattern of experts regarding the reduction of students' tendency to physical activity in school. They found that, according to experts, there are 11 distinct mental patterns in reducing students' inclination to exercise and physical activity in schools. Also, in this research, the necessity of designing a comprehensive system for talent identification in school sports, compensating for the lack of administrative and educational facilities, mass media attention to school sports, the existence of rules in line with educational programs and paying attention to the determining role of principals in knowledge activities. Students at school were acknowledged. In their research, Zagato et al. (2011) extracted key performance factors in table tennis. Gender, age, nationality, height, weight, style of play, attack and defense techniques, gait, equipment and facilities, playing conditions, etc. were among the factors affecting the performance of table tennis players that were identified by Ivan et al. . In a study entitled "Challenges and Opportunities for the Development of Table Tennis as a Means of Peace in Zimbabwe", McAuer and Man Douga (2012) stated that table tennis could be a very effective and powerful tool. To play a role in building peace in countries like Zimbabwe. This is because values such as fair play, transparency, tolerance, competition and synergy, which are all part of the sport of table tennis, can somehow facilitate and strengthen peace and friendship. Rankin (2012) in a study entitled Recognizing barriers to sports participation, classified barriers into three categories: logistical (cost, communication, competence, geography), psychological (personal perception and attitude of others) and physical (facilities, health facilities and facilities) . In their research, Moniorana et al. (2015) examined the key tactical and technical factors influencing table tennis. The findings indicate the improvement of technique and tactics in three areas of attack, counter-attack and defense for coaches. Rao et al. (2016) in a study examined the challenges of sports development and the level of participation of women cyclists and examined the motivations, limitations and support reported by these people and concluded that a wide range of factors including personal characteristics and factors Existing in the physical-social environment were identified as barriers to participation by the participants.

On the other hand, pathology is equivalent to the word pathology, which means identifying the causes and roots of the factors that play a role in the occurrence of crisis in various phenomena, and these factors can disrupt the process of maturation and efficiency of the phenomena. The purpose of pathology is to find the cause or causes of stagnation or crisis in the natural process of phenomena and activities. On the other hand, the pathology of data collection is defined in order to interact effectively and beneficially in order to solve problems, challenges, pressures and environmental constraints in different societies (Samuel, 2010). Pathology means the pathology and diagnosis of the causes of injuries to a specific system under study. This science, which is widely used in life sciences, also has a status and prestige in humanities, so that the pathology of the organization has attracted the attention of humanities scientists under the same title (McGavin and Zakhari, 2006). In addition to the concepts and methods of behavioral sciences, the term pathology also considers other concepts and methods of knowledge management in the field of strategic planning, process reengineering, organizational productivity, and so on. Low level of productivity in terms of efficiency and effectiveness is not only due to the shortcomings and inadequacies of the human factor, but also other factors such as improper organization, weak control system, inappropriate bVeden work processes, etc. play a role in this that should be examined (Siyadi, 2019). Therefore, in order to codify the classification and rooting of injuries and provide a suitable solution for correction, pathology models can be used as valuable tools for improvement; According to Anderson, the mental model should not be used to study the organization; Because the researcher's perceptions guide the study process and influence their actions and participate in generalizing the project outcomes. For this purpose, the Q method 
was used as a mixed method that can accurately categorize, classify and label the opinions and opinions of research experts on the subject.

In general, table tennis is one of the most popular sports in the international arena, to the extent that many countries around the world have introduced it as their national sport. Iran is no exception to this issue and table tennis is mentioned as one of the most popular sports in the country. The enthusiastic welcome of people of all ages in different parts of the field, such as neighborhoods, schools, universities and clubs, etc., are all reasons for the high claim. Accordingly, investing and entering this field in order to analyze and recognize the phenomena related to it is an inescapable thing. Therefore, in order to advance the great goals, develop the championship and professionalism and gain international positions in the country, scientifically and logically study the whole phenomenon of this popular sport in the country and with a realistic view of its success and harmful factors. Showed. Why is sport not so important and what are the problems facing this sport that can prevent its growth and development? In the meantime, the opinion of knowledgeable and expert people in this field should be asked; Who are as pioneers and even professionals in this field. As a result of this research, it seeks to answer the question of what are the deterrents to professional table tennis in Iran and what is the mental model of experts in this regard?

\section{Methodology}

The present article is based on the purpose of applied research; In terms of the nature of exploratory research; In terms of data collection, it is a descriptive-survey research, and due to its application, Q methodology is a mixed (quantitative-qualitative) research. Q methodology is a method that includes the simultaneous use of quantitative and qualitative methods; Therefore, the results of the study and analysis of the information obtained in this study include the extraction of the main factors mentioned in previous studies and the alignment of these studies in addition to conducting a $\mathrm{Q}$ interview to extract the views and opinions of experts. Also, from a quantitative point of view, statistical methods are used to categorize people such as Q factor analysis and principal component analysis. Since the main purpose of this method is to reveal different mental patterns and not count the number of people with different thoughts, research method Quality is also closer (Harandi, 2008).

Q methodology is a technique by which the mentality of individuals is studied. Because the prevailing approach to research is to identify and categorize the views, opinions and mindsets of experts and thinkers towards the harms that can lead to a deeper understanding and boom of the prevailing realities for the diversity of projects in the country. Help us, the Q methodology has been used to help achieve this. This method uses subjective ideas to construct a typology of different perspectives. In fact, Q is a technical methodology that enables the researcher to identify and classify individual perceptions and beliefs, and secondly to categorize groups of individuals based on their perceptions (Khoshgovianfar, 2007).

\section{Research implementation steps}

After the title and scope of the research, the executive steps of the research are summarized in Table 1, respectively; 
Table 1. Research implementation steps

Number of executive steps

1 Refer to the subject literature, search and select appropriate articles, collect discourse space and extract the main factors and harms

2 interviews and surveys of experts

3 Evaluate and summarize the discourse space

4 Select the final Q phrases (Q cards)

5 Create Q categories

6 Selection of participants from among specialists and experts

7 Sorting Q samples in Q charts

8 Statistical data analysis (Q factor analysis)

Description of Q methodological steps

In the first step, the research discourse space should be collected, ie a collection of various materials related to the research topic that is discussed among the people of the discourse and a combination of sources including structured interviews, debates, scientific and research articles, chapters of books, Constructive, stable, and diverse opinions are notes and the like. Therefore, from these appropriate and desirable phrases that were obtained from the theoretical foundations of the research, ie the findings and results of the interviews, those that were highly related to the pathology of table tennis were collected in a total of 40 phrases.

Table 2. Q phrases

Lack of financial credits in table tennis teams of provinces and cities

Lack of codified and long-term planning to discover and cultivate talents in the country

Lack of modern sports facilities and equipment

High training costs

Insufficient attention to the development of women's sports in this field

Lack of colorful media presence in this sport

Weaknesses in the basic and modern training of educators (development in the field of education)

Inability to hold classes and retraining courses for educators

Lack of support for talent and coaching coaches in the country

Lack of regular provincial and national games

Weakness in holding related gamesTo the basic age categories

Failure to hold specialized meetings and conferences on table tennis

Lack of basic and modern training in table tennis refereeing

Lack of cooperation of the federation with education regarding the discovery of talented people in the country's schools

Inability to attract sponsors and sponsors

Lack of international seats

Lack of long-term planning for success in world and Olympic tournaments 
Lack of support for private clubs

Lack of hardware and software facilities

Lack of scientific development of table tennis

Lack of proper structure in table tennis teams

Weakness in spreading the game in public places

Not paying attention to the livelihood of your heroes and veterans

Lack of employment of young and specialized force

Weakness in research

Lack of specialized table tennis schools and academies

Lack of attention in empowering members of the Table Tennis Federation

These 40 phrases are related to injuries in the sport of table tennis in the country. After reviewing in two stages by two sports management experts, making the necessary changes for the validity of the phrases, such as removing similar and repetitive phrases or removing their ambiguity, 27 phrases The final's sample of Q was selected in the present study, which are specified in Table 2 of these expressions. The code of each of these sample expressions is one and in the Q cards, on which subsequent calculations and analyzes are performed, are given in this table.

Each of the expressions in the table above was written with its own code on a card called the Q card. The next step is to sort the Q diagram by the research participants. Typically, in the $\mathrm{Q}$ method, selecting between twenty to eighty samples of the subjects is sufficient to achieve different views on a subject (Khoshgovianfar, 2007). Therefore, the selection of participants is not done through probabilistic sampling methods, but the sample of individuals is usually purposefully selected on a small scale. In the present study, among the active coaches in the Premier League, veterans and elites in table tennis, 21 people Were selected as research participants. This selection was made using a combination of purposeful and unlikely sampling and snowball sampling. The selection of participants in this study was based on "their close relationship with the research topic" and "the importance of their presence in the research". In the next step, the participants were asked to place each of the cards on the Q chart according to the $\mathrm{Q}$ sorting instructions. To conduct this research, Q diagram with distribution to normal with forced distribution has been used. The chart was embedded by participants to place $27 \mathrm{Q}$ terms ranging from -5 , which means complete opposition to the term, to +5 , which means complete agreement with the Q statement. After sorting by the research participants, the scoring method of each participant, a special form designed for this purpose, was recorded. Participants' sorting data were entered in SPSS software to identify the different mindsets of the participants by means of factor analysis and to answer the research questions.

\section{Validity and reliability in Q method}

The face validity of $\mathrm{Q}$ charts and expressions was confirmed by 3 sports management experts. In addition, the feedback that the researcher received from the participants when sorting the cards indicated that appropriate phrases had been selected to assess the subject of the research. Cronbach's alpha method was used to assess the validity or reliability of the study. Cronbach's alpha for this study was 0.88 for 21 participants, which indicates the high reliability of Q sample expressions and their sorting results in $\mathrm{Q}$ diagrams. 


\section{Research Findings}

\section{Statistical analysis (Qfactor analysis)}

In this stage of the research, unlike the previous stage where the qualitative method was used, the quantitative research procedure is used to identify similar mindsets among the research participants. For this purpose, Q factor analysis statistical tool is used. Factor analysis method is the main statistical method for analyzing $Q$ data matrix. The basis of this method is also the correlation between "individuals"; Hence, the term "Q factor analysis" is used to emphasize that in the process of factor analysis, individuals are categorized instead of variables. Nevertheless, there is no statistically significant difference between $\mathrm{Q}$ factor analysis and normal factor analysis. Correlation matrix, which is a common method, was used for factor analysis. The agents were rotated by the varimax method, which is a type of orthogonal rotation. It should be noted that the numbers extracted from $\mathrm{Q}$ factor analysis are principal components.

Shows that according to the views of individuals, a total of 9 factors have been identified, which explain and cover about $91.31 \%$ of the variance.

As mentioned, based on the total table of variances explained in the number table, the identified injuries can be expressed based on the importance of mental patterns. Thus, the barriers identified in mental pattern No. 1 are more important than other mental patterns because they explain $21.37 \%$ of the total variance. Therefore, the significance of the injuries identified in the 9 mental patterns is the same as in the table. The table below shows the priority of identified injuries based on mental patterns.

\section{Discussion and interpretation of mental patterns}

\section{Mental pattern 1: Sports justice seekers}

According to the common view of these people, insufficient attention to the development of women's sports in this field, weakness in holding games related to basic age groups, lack of hardware and software facilities, lack of employment of young and specialized force and weakness in the research sector. Factors that prevent professional table tennis in Iran. In other words, they believe that if long-term and correct planning to use the hidden talents in the basic age groups and also in the women's section by holding regular competitions in these sections along with creating the required hardware and software facilities. In order to discover and develop these talents, we will not see a significant decrease in the tendency towards table tennis day by day, and naturally we must see weakness in the national teams and the table tennis league of our country. Experience has shown that whenever young people and their potentials are valued, a decent response is received, often beyond imagination, so using and trusting educated, young and professional table tennis players is not only a risk, it certainly is not. It will cause the growth and development of the professional level of table tennis in our dear country.

\section{Mental Pattern 2: Concerned about education}

Based on the mentality and views of the participants in this mental model, not holding specialized meetings and conferences on table tennis, lack of scientific development of table tennis, lack of attention to the livelihoods of champions and veterans and lack of attention to empowering members of the Table Tennis Federation They are considered as a deterrent to professional table tennis in Iran. In other words, they believe that the mere knowledge of the past and the lack of equipping the country's table tennis coaches and practitioners with modern weapons have not only 
caused our country to lag behind its competitors and counterparts in the world, but also one of the important reasons. The quality decline of the country's professional table tennis competitions will be in the not too distant future. In the digital age and in this small global village where access to modern world knowledge and its localization to benefit and make optimal use of this boiling source of science and knowledge is not a problem, not using these huge assets to empower active manpower In the field of sports and especially table tennis, it will be a very big and unforgivable mistake that will not give any justification.

\section{Important 3: 2 (c) mental pattern throughout history (money and party)}

According to this group of people, the following issues are one of the most important factors in table tennis that will cause the lack of progress and development of this sport at various national and international levels. Lack of financial credits in table tennis teams of provinces and cities can be mentioned as the most important factor in this field. Other important factors in this mental model are the lack of colorful presence of the media in this sport, as well as the inability to hold classes and retraining courses for coaches, which are the result of the first factor; Because a sport is attractive to the media when there is a good turnover and the media can use this turnover and the huge number of viewers to achieve their goals and profitability. A variety of audio-visual media such as television and radio, and a variety of print media such as newspapers and magazines, as well as digital and Internet media, can have some impact on sport. Undoubtedly, paying too much attention to the margins instead of the text, lack of expertise in reviewing issues related to table tennis, forgetting about teaching table tennis from the language of national and social media, not planning and implementing appropriate promotional advertisements Attracting teenagers to sports, especially table tennis, and the like, is one of the harms inflicted on the body of sports by the sports media, and experts have become concerned about this issue in the future of professional table tennis in the country. Also, lack of sufficient budget and lack of adequate sponsors has caused the inability of the delegations and the federation to hold classes and retraining courses for coaches, which will be a huge blow to the professional table tennis in our country in the long run. Brought. Lack of international seats is another important factor in this mental model that can seriously challenge our country's professional table tennis. It is very clear that in order to shine in the international and global arenas, in addition to technical ability and regular training, it needs psychological support and sometimes the power to realize the right from higher authorities, and this lack of seats at the international level will make our athletes Be competent and capable of not being able to voice the protest through a credible channel (such as Iran's representative in one of the international federations)Reach out to the authorities and defend their lost rights.

\section{Mental pattern 4: It is not possible to destroy the suffering of treasure}

According to the mentality of this group of experts, weakness in the basic and modern training of coaches (development in the education sector), lack of support for talent coaches and player development in the country, lack of cooperation between the federation and education to discover talented people in schools and weakness in development Playing in public places is one of the biggest deterrents to professional table tennis in Iran. The implication of this mental pattern is that experts believe that in table tennis we are accustomed to eating ready-made morsels that we have not bothered to make. To put it more clearly, without training coaches with the power to find talent and the ability to cultivate talent, and without investing in talent discovery, especially in a place like education that is a mine of God-given talents, and without any effort to train, introduce and expand table tennis as A public sport, how can one expect to raise champions with world- 
class standards who can shine at the highest levels and raise the name of Iran and Iranians on the top peaks of table tennis in the world? Unless we are waiting for a miracle that unfortunately the other era of miracles is over.

\section{Mental pattern 5: Slowly but steadily forward}

One of the important factors mentioned in this mental model is the lack of regular provincial and national games and the inability to attract sponsors and sponsors. One of the most important problems that the coaches and the heads of the city boards always face is the lack of a regular and regular annual program in holding provincial and national competitions, both in the age and higher categories. Unfortunately, this lack of a regular schedule will not only prevent the coach from preparing a proper training program to prepare and put his athletes in the best condition before the match, and will not only cause confusion and discouragement and even the decision to withdraw the athlete from the sport. It will cause the heads of delegations and team dispatchers not to act at the right time and with the plan to attract sponsors, and we often see that some players or teams in the last minutes before dispatch due to inability to attract a suitable sponsor. They refuse to participate in competitions and this also causes a qualitative decline in the level of competition.

\section{Mental pattern 6: Update is not just for software}

These people target one of the most important human resources in table tennis and consider the lack of basic and modern training in the field of table tennis refereeing as one of the most important deterrents to professional table tennis in the country. What is clear is that the referees play a very key and decisive role in sports competitions in any field, and the existence of a classical and so-called outdated point of view and science of refereeing is not acceptable in any sport and will affect the quality of competitions in that sport. ثشدTherefore, we conclude that the existence of knowledgeable and up-to-date referees who have learned the latest world knowledge in principle is one of the requirements that no matter how much is spent and invested in it, its return will be visible in competitions in the short term. Lack of modern sports facilities and equipment along with refereeing is another influential factor that can not be easily ignored. Use and enjoyment of modern and up-to-date facilities in the world, whether in the field of training and new bodybuilding equipment and physical fitness for table tennis, or in the tools and equipment needed for professional and specialized exercises in table tennis, including shoes, tables, rackets, Tours, balls, etc., in addition to accelerating the growth of players and their learning, will enable the player to express his maximum ability and talent. Some sports may not require modern equipment, but those who have even held a table tennis racket once understand well how much the use of the best facilities can affect the quality of a person's game, even in sensitive competitions. Make the difference between the final winner and the loser.

\section{Mental pattern 7: Economic pressure from all directions}

High training costs are one of the most important concerns of respected experts in this mental model in table tennis in Iran. Unfortunately, with the economic pressures that are being put on the body of society in the coming crises, ordinary life is becoming more difficult day by day and it is becoming very difficult to cope with the daily expenses of working life. Now, in this situation, imagine an athlete who, at the beginning of a tumultuous path, becomes a professional tennis player and a star of national and international arenas, and needs to grow and improve further and reach the necessary standards by purchasing. Support the best standard and up-to-date equipment in the world, as well as the best and healthiest nutrition to maintain fitness and fitness, as well as 
gain the necessary energy to perform regular exercises. In this situation, while the costs of food and supplies such as proper shoes and standard rackets are increasing day by day, and although once a day we see the prices multiply for the person who is at the beginning of the road and no $\mathrm{He}$ also does not earn any income from table tennis and due to his full-time and professional training, he cannot find a full-time and lucrative job for himself. Is there a way he can just continue playing tennis? Progress and professionalization of the offer.

\section{Mental Model 8: Planning Strategists}

The lack of long-term planning that leads to success in world and Olympic tournaments is a factor pointed out by this group of experts. Most programs thatIn table tennis, they are cast crosssectionally and according to the conditions and requirements of the time, and the vacancy of strategic and long-term plans in table tennis in the country is properly felt. This issue is well identified by this group of experts and is considered as one of the important challenges facing professional table tennis in the country. A principled, scientific, and long-term expert program can be like a beacon to guide and guide the general table tennis management system of the country, which, by formulating a policy and presenting appropriate strategies, will open the way for the continuous growth and development of this sport. Greatly reduce the time and facilities; Unfortunately, this case is felt not only in table tennis, but also in most sports in our country, and if there is, it can lead to many problems and problems due to lack of planning and the lack of proper strategies in this Prevent sports and other disciplines.

\section{Mental Model 9: 3 (d) basic mental pattern = expertise, commitment, perseverance}

The lack of specialized table tennis schools and academies, along with the lack of longterm planning to discover and nurture talents in the country and the lack of regular provincial and national games, explain other deterrents to professional table tennis in Iran. Although table tennis is one of the most fun sports in our country, but we still see that the number of academies and clubs that focus professionally and scientifically on cultivating the talents of our country's tennis players is very limited and few. This reluctance to invest in table tennis can be attributed to the lack of applicants for training in this field. The other two perspectives in this mental model can be an explanation for the lack of interest and tendency of newcomers to table tennis. The first view introduces the lack of well-codified and long-term planning to discover and nurture talents in the country, which shows that the lack of a comprehensive and specific program and strong legal support in this sport causes parents and athletes not to be interested in this popular sport. The second view points to the lack of proper planning of the table tennis management of the provinces and the country, which, whether intentionally or unintentionally, by holding provincial or national competitions, discourages players and club owners, who sometimes change the field. Non-Hall players or teenagers are drawn to more glamorous disciplines and even the dissolution of specialized zinc tennis academies and clubs due to inability to pay due to the lack of beginners in table tennis.

\section{Conclusions and research suggestions}

Based on what has been said, the main deterrents in Iranian professional table tennis were prioritized based on nine mental patterns. These mental patterns were then discussed and interpreted. In this section, the researcher seeks to answer the question of what are the solutions to deal with the deterrents ahead; 
Holding regular provincial and national competitions in the women's section is one of the most important issues that should be emphasized because women, as an important part of society, have the right to observe justice between them and men in any sport. Since the research of Ivan et al. (2011) considers gender as one of the key functional factors in table tennis, we should not neglect to pay attention to either sex and the way of growth and development should be planned for both men and women. He paved the way for the right and just, so that Iranian women could take the lead from men in the arenas of international competition and engrave the name of dear Iran on the peaks of world honor. Rich et al. (2016) in a study on the limitations of women's leisure time in communities also concluded that using the media can improve the image of an athlete. At the same time, they emphasized on supporting female athletes. In this field, too, we must pay attention to female athletes and observe justice and equality in both sexes. One of the issues that is highly emphasized in world sports today is the discovery and development of talents from infancy and adolescence and the emphasis on regular and planned training and competitions in the basic age categories. Since the sports findings of Egin et al. (2016) who state that the system of talent discovery and training system are the most important factors in evaluating the process of talent management in table tennis, this is a confirmation of this claim and also according to the belief that the team Strong adults in any sport are the result of several strong grassroots teams in that sport; On the other hand, Manksari et al. (2014) in their research entitled Identifying the Challenges of Iranian Championship Sports in the Olympic-medal-winning disciplines reported that talent and talent development, media, economy, equipment and facilities as the most important challenges Are known. There was also a significant difference between the views of the elites in the components of talent identification, media, legal support and education. Therefore, it is expected that with legal, official and financial support from schools and specialized talent identification academies and also in consultation with the Ministry of Education to include the popular table tennis training in the physical education curriculum, it will discover, grow and nurture the many talents of these children. Provide borders and canvas. Another important and vital issue that should be considered is professional and specialized training, both in terms of developing the knowledge of coaches and players, and among table tennis referees. Findings of Emadi et al. (2014) who studied the effect of modern and traditional educational methods in table tennis, significant differences and correct execution of movements in table tennis in a modern educational way Shows that the traditional method is completely related to the findings of the analysis of mental patterns in this study. Updating the facilities in clubs and table tennis teams is one of the most important missions facing table tennis in our country on the way to becoming a professional. Zaraatgar (1396) studied the factors affecting the development of badminton in Mazandaran province and concluded that the lack of managers with business ideas and expertise and income generation in sports are the most important factors, then educational index, championship index, respectively. Championship Index, Media Index, Equipment and Facilities are involved in the development of badminton. On the other hand, Ghasemi Nejad (2011) research with the approach of the effect of modern facilities and equipment in table tennis showed that the use of new and up-to-date educational videos has a positive and significant effect on learning table tennis, which complements and confirms the findings of this study. Be. Financial support and efforts to attract strong financial sponsors to invest in table tennis, as well as financial support to athletes in the form of establishing funds to support the country's table tennis elite can be the ground for the growth and development of worthy youth of this region. Provide and consequently cause the growth of table tennis in the country. Firoozi et al. (2012) examined the challenges and problems of the medal-winning disciplines of athletics, sailing and swimming in Iran and reported that the lack of long-term planning and lack of media support as the most important challenges facing the discipline. Medals are rewarding. Since the correct training of professional players, 
paying attention to the physiological criteria of the players, performing standard and purposeful exercises in line with modern training were among the cases that Armandnia (2008) in his research to reduce the gap between Iranian table tennis and zinc tennis The advanced table in the world stated that this correct and purposeful training of players will not be necessary except in the shadow of meeting the basic demands and needs of the hardware and software they need, indicating the great importance of proper, adequate and timely financial support of young talents. This is a sport. Consulting with municipalities as officials and agents of public sports in cities to equip public sports venues with the basic facilities of table tennis will make people more inclined to this beautiful sport, and finally, given the importance of planning, especially strategic planning. In the country's sports, especially in the sports and youth departments of the provinces and sports delegations, as well as the lack of sufficient research in understanding the internal and external environment of table tennis in the country and the lack of a codified and regular strategic plan in table tennis is recommended. Using his educated and academic talents as soon as possible, he analyzes the current situation, opportunities and threats and a long-term and systematic roadmap to achieve great goals such as training world and Olympic champions and training referees at the first level of competitions between International as well as the effort to win important seats in the continental and global federations to make continuous and systematic efforts and planning.

\section{References}

Azmendnia, Mehdi. (1387). Comparison of structural, anthropometric and physiological characteristics of table tennis elite players. Journal of Applied Sports Physiology. 4 (8): 67-78.

Rashid Lemir, Amir, Dehghan, Amin. (1394). Development of a strategic plan of the General Directorate of Sports and Youth of Khorasan Razavi Province in the field of sports and physical education. Sports Management, 5 (4). Pages (179-198).

Shojaei Vahid, Tajar Farshad, Soleimani Tappeh Sari Bahareh, Doosti Morteza (2012). Strategic planning of sports tourism in Mazandaran province. Journal of Geographical Space: Fall 2012, Volume 12, Number 39; From page 173 to page 194.

Taheri Hooman, Taifi Nasrabadi Abbas Ali, Amiri Jassem (2015). Development of a strategic plan for the development of championship sports in Lorestan province by SWOT method. National Conference on New Achievements in Physical Education and Sports. Chabahar. The second period.

Emadi, Seyed Rasoul, Shabani Bahar, Gholamreza, Nematzadeh, Sara. (1393). Comparison of the effect of training using educational software and traditional methods in performing forehand and backhand services of table tennis. Contemporary Research in Sports Management, 4 (8): 40-29.

Mankarsi, Shahram, Safania, Ali Mohammad, Qasemi, Hamid. (1393). Identifying the challenges of Iranian championship sports in Olympic medal-winning disciplines. Strategic studies of sports and youth. Volume 14, Number 27.

Burns, L., Weissensteiner, J. R., \& Cohen, M. (2019). Lifestyles and mindsets of Olympic, Paralympic and world champions: is an integrated approach the key to elite performance ?. British Journal of Sports Medicine, 53 (13), 818-824.

Coalter, F. (2010). The politics of sport-for-development: Limited focus programs and broad gauge problems ?. International review for the sociology of sport, 45 (3), 295-314. 
Firouzi, M., Razavi, H., Farzan, F. (2012). Review the Challenges and Challenges of Medal Games in Iran Diving, Sailing and Swimming. Sport management and motor behavior research. 8 (15).

Gheorghe C. MANAGERS AND HUMAN RESOURCE MANAGEMENT IN FOOTBALL. Rev Econ. 2015; 67 (5): 148-64.

Jarvie, G. (2013). Sport, culture and society: an introduction. Routledge.

Kang, S. K., \& Bodenhausen, G. V. (2015). Multiple identities in social perception and interaction: Challenges and opportunities. Annual review of psychology, 66, 547-574.

Kashtidar, M., Sahebkaran, M. A. S., Razavi, S. M, kalushi, M. (2018). Identification and Modeling of General Sports Development Strategies among Female Students of Birjand University. Journal of Research in Sport Education. Number 14: 254-234.

Kashtidar, M., Shsji, K., Rohi Behloli Ahmadi, S., Fatizadeh, S. F. (2018). Identifying the Mental Pattern of Experts on Reducing Students' Attitudes toward Physical Activity at School (Using Qi Methodology). Journal of Applied Research in Sport Management, 7 (1): 2211.

Makwerere, D., \& Mandoga, E. (2012). Challenges and opportunities in developing football as a vehicle for peacebuilding in Zimbabwe.

McGavin, M. D., \& Zachary, J. F. (2006). Pathologic basis of veterinary disease. Elsevier Health Sciences.

Munivrana, G., Petrinović, L. Z., \& Kondrič, M. (2015). Structural analysis of technical-tactical elements in table tennis and their role in different playing zones. Journal of Human Kinetics, 47 (1), 197-214.

Nagy ZI. The Role of Legal Forms in Professional Football. Acta Polytech Hungarica. 2013; 10 (4): 209-27.

Rankin, A. m. (2012), Understanding the barriers to Participation in sport April 2012, www.efds.co.uk.

Rowe, K., Shilbury, D., Ferkins, L., \& Hinckson, E. (2016). Challenges for sport development: Women's entry level cycling participation. Sport Management Review, 19 (4), 417-430.

Samuel, Y. (2010). Organizational pathology: Life and death of organizations. Transaction publishers.

Sayyadi, M. (2019). The Transformational Leader's Role in Organizational Design and Knowledge Management Performance. International Leadership Journal, 11 (3).

Wang, J., Zhao, K., Deng, D., Cao, A., Xie, X., Zhou, Z., ... \& Wu, Y. (2019). Tac-Simur: Tacticbased simulative visual analytics of table tennis. IEEE transactions on visualization and computer graphics, 26 (1), 407-417.

Zagatto, A. M., Papoti, M., dos Reis, I. G., \& Gobatto, C. A. (2011). Comparison of anaerobic threshold, oxygen uptake and heart rate between specific table tennis procedure and conventional ergometers. Intern J Table Tennis Scie, 7, 24-29.

Zeraatgar, B. (2017). Investigating Factors Affecting Badminton Development in Mazandaran Province. Faculty of Physical Education and Sport Sciences and Master Thesis. University of the Shomal. Mazandaran. 